\title{
Evaluation of a nutrition intervention in adolescents of an urban area in Greece: short- and long-term effects of the VYRONAS study
}

\author{
Constantinos Mihas ${ }^{1, *}$, Anargiros Mariolis ${ }^{2}$, Yannis Manios ${ }^{3}$, Androniki Naska ${ }^{4}$, \\ Angeliki Arapaki ${ }^{2}$, Theodoros Mariolis-Sapsakos ${ }^{2}$ and Yannis Tountas ${ }^{4}$ \\ 'Department of Internal Medicine, General Hospital of Kimi 'G. Papanikolaou', Kimi, Evia, 34003 Greece: \\ ${ }^{2}$ Health Centre of Vyronas, Athens, Greece: ${ }^{3}$ Department of Nutrition and Dietetics, Harokopio University, \\ Athens, Greece: ${ }^{4}$ Department of Hygiene, Epidemiology and Medical Statistics, School of Medicine, \\ University of Athens, Athens, Greece
}

Submitted 21 May 2009: Accepted 21 August 2009: First published online 28 September 2009

\begin{abstract}
Objective: To assess the short-term (15-d) and long-term (12-month) effects of a school-based health and nutrition education intervention on diet, nutrition intake and BMI.

Design: The 12-week teacher-implemented intervention in combination with seminars organized for parents was aimed at improving children's diet and nutrition knowledge. The intervention took place between September 2007 and January 2008. The participants were randomized to two study groups, the intervention group (IG) and control group (CG), and were examined prior to the intervention on a variety of health knowledge, dietary, behavioural and anthropometric indices. The same measurements were collected $15 \mathrm{~d}$ and 1 year after the intervention.

Setting: All high schools in Vyronas, a densely populated district of Athens, Greece. Subjects: The sample consisted of 191 students aged 12-13 years.

Results: Twelve months after the intervention, the programme was effective in reducing various indices in the IG compared with baseline findings (BMI: $23 \cdot 3$ (SD $2 \cdot 8) v .24 \cdot 0(\mathrm{SD} 3 \cdot 1) \mathrm{kg} / \mathrm{m}^{2}, P<0 \cdot 001$; daily energy intake: $8112 \cdot 4(\mathrm{SD} 1412 \cdot 4) v$. $8503 \cdot 3$ (SD $1419 \cdot 3$ ) $\mathrm{kJ} / \mathrm{d}, P<0 \cdot 001$; total fat intake: $31 \cdot 3$ (SD $4 \cdot 4$ ) $v .35 \cdot 4(\mathrm{SD} 4 \cdot 7$ ) \% of daily energy, $P<0 \cdot 001)$. Except for BMI, decreases in the aforementioned indices were also observed $15 \mathrm{~d}$ after the intervention. In addition, students of the IG reduced their weekly consumption of red meat and non-home-made meals and increased their frequency of fruit and breakfast cereal consumption.

Conclusions: The beneficial effects of this nutrition education intervention among adolescents may highlight the potential of such programmes in the prevention of obesity.
\end{abstract}

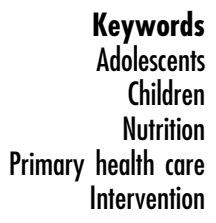

Obesity is the most prevalent nutrition-related problem during childhood and adolescence. More than 35\% of school-age children in the USA were overweight (including obesity) in 2003- $4^{(1)}$. In Spain, a Mediterranean country, the relative frequency of obese children $6-17$ years of age was $6.3 \%$ in a $2004-6$ cohort, following an increasing trend ${ }^{(2)}$; while the prevalence of overweight or obese boys and girls reached 12.5 and $2 \cdot 1 \%$ and 14.8 and $2.9 \%$, respectively, in a sample of 4115 Norwegian children aged 4-15 years between 2003 and $2006^{(3)}$. Greece is no exception, having the second highest prevalence of adolescent (14-17 years of age) obesity (22\%), based on the International Obesity Taskforce classification ${ }^{(4)}$.

The most significant long-term consequence of childhood obesity is its persistence into adulthood, leading to an increased CVD risk ${ }^{(5)}$. Recent data have reaffirmed the link between risk factor exposure in childhood and adolescence and preclinical atherosclerosis in adulthood $^{(6,7)}$. Greece has one of the most rapidly rising death rates due to CVD, which now constitutes the main cause of morbidity and mortality ${ }^{(8)}$. This trend may be attributed to the abandonment of the traditional Mediterranean diet in favour of a more 'Westernized' one combined with limited awareness of health dietary issues and a sedentary lifestyle ${ }^{(9,10)}$. In addition, childhood obesity has been associated with insulin resistance, type 2 diabetes mellitus, the metabolic syndrome, orthopaedic problems ${ }^{(11)}$ and even some forms of cancer ${ }^{(12)}$.

The beneficial effect of a healthy diet on cardiovascular health is well recognized. The adoption of a diet low in 
saturated fat and rich in olive oil, fruits and vegetables favourably affects certain health indices and reduces the odds of CVD risk ${ }^{(13,14)}$. These data suggest that a change towards a healthier dietary pattern could act protectively for preventing adverse health effects in the future.

The beneficial potential of school-based nutrition education interventions in achieving both short-term and long-term dietary changes is well established, both internationally ${ }^{(15,16)}$ and in Greece ${ }^{(17)}$. However, the absence of data from school-based programmes in an urban setting, and especially in adolescents, led us to implement a concise (12-week) nutrition education programme in children aged 12-13 years studying in high schools in Athens, Greece. The aim of the study was to evaluate the short-term (15-d) and long-term (12-month) effects of a 12-week school-based health and nutrition interventional programme regarding energy and nutrient intake, dietary changes and BMI.

\section{Experimental methods}

\section{Subjects}

The data were collected during the VYRONAS (Vyronas Youth Regarding Obesity, Nutrition and Attitudinal Styles) study ${ }^{(18-22)}$, which was carried out by the Health Centre of Vyronas in collaboration with the Department of Nutrition Science and Dietetics of Harokopio University of Athens and the Department of Hygiene and Epidemiology of the University of Athens Medical School.

In the study, 342 adolescents aged 12-13 years who were students ( 7 th grade) of all ( $n 5)$ high schools located in Vyronas district, Athens, Greece, were initially eligible. The Vyronas area was selected because it represents the socio-economic status of the citizens of Athens ${ }^{(23)}$. The municipality of Vyronas is medium-sized, thus represents an average region of the Athens metropolitan area. In addition, Vyronas includes the majority of the socioeconomic classes $^{(23)}$ and therefore is a close representation of the capital's population in terms of social status. Of the initially eligible students, 309 voluntarily were interested in participating in the study.

Prior to their enrolment in the study, both the adolescents and their parents or guardians were fully informed about the objectives and methods of the study and signed a consent form. After recruitment, all participants were examined by general practitioners at the Health Centre of Vyronas. Subjects who had an organic cause for high or low weight, received any medication that might interfere with growth or weight control, or were on specific diets were excluded from the study. Twenty-three children were excluded for the aforementioned reasons. The sample size calculation for the study was based on previously reported ${ }^{(24)}$ intervention changes in energy intake among children. In order to detect standardized differences larger than $5 \%$ in dietary intake (main dependent variable) between the study groups - intervention group (IG) and

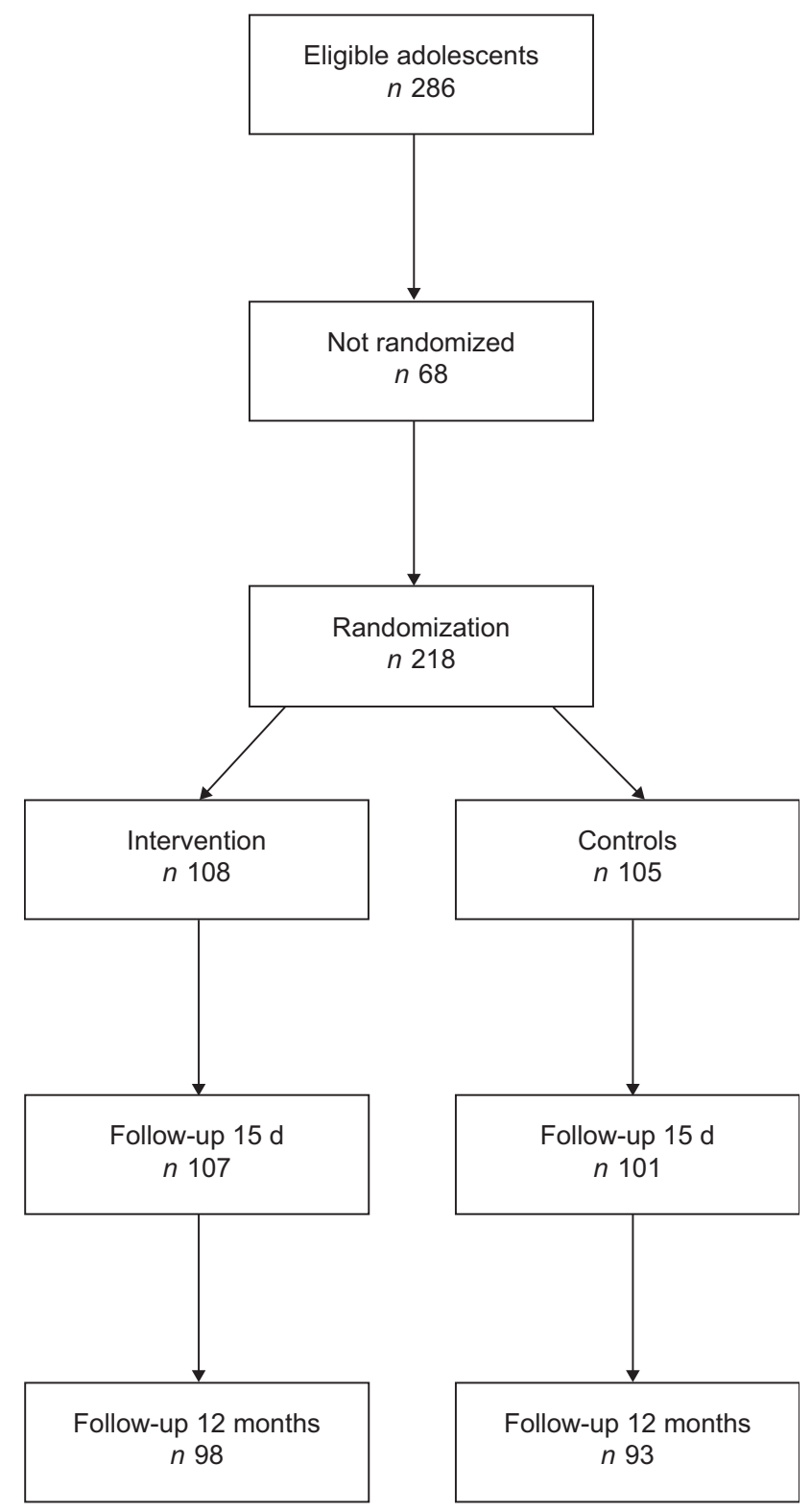

Fig. 1 Flow chart of the study

control group (CG) - before and after the intervention, achieving $90 \%$ statistical power at a probability level $<0 \cdot 05$, eighty-seven subjects should be recruited in each study group. In order to counter potential low response and drop-outs, the authors increased this number by $25 \%$ to a total of 109 for each study group. From the 286 finally eligible students, 218 were assigned randomly using a computerized random number generator in order to participate in the study in two groups of 109 students (IG and CG). Because of the nature of the intervention, blinding was not feasible. During the intervention period, five subjects $(4.6 \%)$ withdrew. Participation rates for the $15-\mathrm{d}$ and 12-month evaluation were $98 \cdot 2 \%(n$ 107) and $89 \cdot 9 \%$ ( $n$ 98) for the IG and $92 \cdot 7 \%(n$ 101) and $85 \cdot 3 \%$ ( $n$ 93) for the CG, respectively (Fig. 1). Reasons for withdrawals 
included health problems, lack of interest and move to other schools.

The study protocol, including data collection, was approved by the Ethics Committee of the Vyronas Health Centre and was in accordance with the Helsinki Declaration of 1975, as revised in 2000 with notes of clarification of 2002 and 2004, and the Guidelines for the Ethical Conduct of Medical Research Involving Children as revised in 2000 by the Royal College of Paediatrics and Child Health.

\section{School-based bealtb education implementation}

The health profile components of the 'Know Your Body' school health promotion programme of the American Health Foundation ${ }^{(25)}$, a school-based intervention study of Manios et $a l^{(26)}$ and the newly developed material for health promotion activities for children 9-12 years old covering the thematic areas of 'Nutrition-dietary habits' and 'Physical activity and health' (funded by the Ministry of Education and the National Foundation for the Youth) were adapted, modified and supplemented to suit our sample. All of the aforementioned programmes and the current work have been based on the Social Learning Theory model ${ }^{(27)}$. This model proposes that human behaviour is the result of the interaction and cumulative impact of personal, environmental and behavioural characteristics. Multi-component workbooks covering mainly dietary issues, but also dental health hygiene and consumption attitudes, were produced with each student being supplied a workbook. The health and nutrition components of the programme were conducted by the class home economics teacher supervised by a health visitor or a family doctor and incorporated $12 \mathrm{~h}$ of classroom material during 12 weeks (28 September 2007 to 30 January 2008). However, since knowledge alone cannot bring behavioural changes, the intervention programme considered the interactions among environmental, cognitive and behavioural factors, for which Social Learning Theory provides the theoretical framework ${ }^{(28)}$. Classroom modules were designed to develop behavioural capability, expectations and self-efficacy for healthful eating and healthy foods selection. Learning activities were designed to influence expectancies that placed an important value on achieving these behaviours. Several motivational methods and strategies were used for increasing skills and self-efficacy (i.e. modelling, guided practice, enactment), achieving better self-monitoring (i.e. problem solving, goal setting), changing attitudes and beliefs (i.e. self reevaluation, environmental re-evaluation, arguments, modelling, direct experience) and changing social influence (i.e. modelling, mobilizing social support). Cues and reinforcing messages in the form of posters and displays were provided in the classroom.

This educational intervention was teacher-delivered. After teachers were provided with preparatory teaching and classroom materials, they undertook special seminars that were designed and conducted to the intervention classes. In cooperation with the school directors, two $3 \mathrm{~h}$ seminars were performed by the authors. The aims of the seminars were: (i) to familiarize teachers with the objectives of the programme and their role therein; and (ii) to increase teachers' awareness of the significance of incorporating health and nutrition in their curriculum.

It is generally recognized that the family plays an important role in shaping children's eating and exercising habits ${ }^{(29)}$. Parental involvement was thus considered to be a critical component of the intervention programme. For this purpose, after the end of the baseline examinations, two meetings were organized whereby parents in the IG were given a file containing their child's screening results. During these meetings, presentations on the importance of topics relevant to the dietary habits of children were issued to improve the health profile of the children and prevent the development of chronic diseases in the future. In addition, a special comment was made for each obese child, although his/her identity was not revealed for privacy reasons. Parents were also encouraged to modify their dietary habits as well as those of their children. These meetings were held at each school where an intervention was conducted and played an extra role: to facilitate parents' participation and provide them with the opportunity to resolve any queries about their children's health. Regarding the CG, an envelope with all medical screening results plus some brief comments were mailed to the parents. The CG did not undertake any health education intervention and no parental educational sessions took place.

\section{Data collection}

Data collection took place in morning school visits during September 2007, February 2008 and February 2009 (baseline, $15 \mathrm{~d}$ and 12 months after the end of the intervention, respectively). A maximum of thirty students were screened each day by the same examiner. Behavioural data were obtained at baseline, whereas students' anthropometric and dietary data were collected in all three examinations following the same procedures ${ }^{(17)}$. Hours of watching television, using a personal computer and playing video games per day were merged to one variable (screen time).

BMI was calculated by dividing weight $(\mathrm{kg})$ by height squared $\left(\mathrm{m}^{2}\right)$. The definitions of overweight and obesity were based on the international BMI cut-off points established for children and youth ${ }^{(30)}$.

The data presented in the current study are based on those students having full data in both evaluation periods (ninety-eight students from the IG and ninety-three from the CG).

\section{Dietary assessment}

The FFQ used for the purposes of the present study had been employed in previous studies of ours ${ }^{(19)}$. It gathered information regarding the participants' dietary habits on a daily or weekly basis. The test-retest reliability of the FFQ 
was estimated by administering it to a sample of twenty ( $\sim 10 \%$ of the total sample) of the eligible students who were not allocated in any study group with a 2-week interval. No significant difference was found between the first and the second assessment.

The students were asked to recall the dietary habits which they had followed for the past week. Before completing the FFQ, an explanatory session on how the FFQ had to be filled out was given by family doctors trained on this subject. Thereafter, the interviewer went through the food list again to clarify entries. To improve the accuracy of food descriptions, standard household measures (cups, tablespoons, portions, cans, etc.) and picture models were used during interviews to define amounts when appropriate. Various foods and beverages usually consumed in Greece and habits pertaining to mealtime behaviours were recorded in sixtythree detailed descriptive questions. The foods were coded and analysed using the US Department of Agriculture Nutrient Database for Standard Reference ${ }^{(31)}$ and the Greek foods using the nutrient tables of the Preventive Medicine and Nutrition Clinic of the University of Crete ${ }^{(32)}$.

\section{Statistical analysis}

The normality of continuous variables was tested with the Shapiro-Wilk statistic. No variable deviated from normality. All categorical data are presented as absolute $(n)$ and relative (\%) frequencies, while continuous variables are presented as mean and standard deviation. Comparison of baseline data was made between study groups using Student's $t$ test for continuous data and Pearson's $\chi^{2}$ test for categorical data. The effects of the intervention were analysed by general linear mixed model analyses estimating the differences between the two study groups regarding the changes observed in nutrient and energy intake and the frequency of various food categories at the $15-\mathrm{d}$ and 12-month follow-up and after adjusting for gender, age and baseline BMI (having tested for any interactions). Interschool variation was also considered by including the random school effect in the model. All statistical tests were considered significant if $P<0 \cdot 05$. Data were analysed using the STATA ${ }^{\mathrm{TM}}$ statistical software package version $9 \cdot 0$ (Stata Corporation, College Station, TX, USA).

\section{Results}

\section{Subject characteristics}

Baseline subject characteristics are summarized in Table 1. No significant differences in age, gender, BMI, overweight/ obesity, smoking, screen time, weekly hours of sport activities, weekly hours of playing or walking and weekly hours of other than sport activities (hobbies) were found between the study groups before the nutrition intervention.

\section{Short-term (15-d) effects}

Changes in daily energy intake and relative intake from total fat, saturated fat, polyunsaturated fat, monounsaturated fat, protein and carbohydrates among the intervention participants and control subjects are summarized in Table 2. The IG reported a significant decrease in daily energy intake and in some nutrient components (total fat, saturated fat). In addition, a significant increase in daily relative consumption of protein was recorded in the same group. No significant difference in both energy intake and nutrient components was found in the CG.

Regarding the weekly consumption frequencies of foods, a significant increase in poultry, ready-to-eat breakfast cereals and fruit consumption and a significant decrease of red meat consumption were found in the IG (Table 3). There was no significant difference in the consumption frequency of any food category in the CG.

Mean BMI did not change significantly $15 \mathrm{~d}$ after the intervention, compared with baseline values, in both study groups (IG: 23.9 (SD 3.2) v. 24.0 (SD $3 \cdot 1) \mathrm{kg} / \mathrm{m}^{2}, P=0 \cdot 495$; CG: $24 \cdot 5$ (sD $3 \cdot 6$ ) v. $24 \cdot 3$ (sD $3 \cdot 3$ ) $\mathrm{kg} / \mathrm{m}^{2}, P=0 \cdot 231$; Fig. 2).

\section{Long-term (12-montb) effects}

Mean daily energy and nutrient intake as they were recorded 12 months after the intervention are shown in Table 2. A significant decrease in daily energy intake

Table 1 Comparison of baseline demographic, anthropometric and lifestyle characteristics between the intervention group (IG) and control group (GC): VYRONAS study, September 2007

\begin{tabular}{|c|c|c|c|c|c|}
\hline \multirow[b]{2}{*}{ Variable } & \multicolumn{2}{|c|}{ IG $(n 98)$} & \multicolumn{2}{|c|}{ CG $(n 93)$} & \multirow[b]{2}{*}{$P$} \\
\hline & Mean & SD & Mean & SD & \\
\hline Age (years) & $13 \cdot 1$ & $0 \cdot 8$ & $13 \cdot 3$ & 0.9 & $0 \cdot 106$ \\
\hline BMI $\left(\mathrm{kg} / \mathrm{m}^{2}\right)$ & $24 \cdot 0$ & $3 \cdot 1$ & $24 \cdot 3$ & $3 \cdot 3$ & 0.518 \\
\hline Watching television/using personal computer/playing video games $(\mathrm{h} / \mathrm{d})$ & $2 \cdot 5$ & $1 \cdot 7$ & $2 \cdot 4$ & $1 \cdot 4$ & 0.659 \\
\hline Sport activities (h/week) & $3 \cdot 3$ & $3 \cdot 6$ & $3 \cdot 0$ & $3 \cdot 1$ & 0.539 \\
\hline Activities excluding sports (hobbies) (h/week) & $5 \cdot 2$ & $3 \cdot 7$ & $4 \cdot 9$ & $3 \cdot 4$ & 0.561 \\
\hline \multirow[t]{2}{*}{ Playing or walking (h/week) } & $2 \cdot 5$ & $1 \cdot 6$ & $2 \cdot 7$ & $2 \cdot 0$ & $0 \cdot 445$ \\
\hline & $n$ & $\%$ & $n$ & $\%$ & \\
\hline Boys (\%) & 48 & $49 \cdot 0$ & 50 & $49 \cdot 5$ & 0.947 \\
\hline Overweight (\%) & 12 & $12 \cdot 2$ & 11 & $11 \cdot 8$ & 0.946 \\
\hline Obese (\%) & 4 & $4 \cdot 1$ & 3 & $3 \cdot 2$ & \\
\hline Regular smokers (\%) & 3 & $3 \cdot 1$ & 4 & $4 \cdot 3$ & 0.649 \\
\hline
\end{tabular}


Table 2 Daily energy and nutrient intake for the intervention group (IG) and control group (CG) at baseline (September 2007) and reexamination $15 \mathrm{~d}$ (February 2008) and 1 year (February 2009) after the intervention: VYRONAS study

\begin{tabular}{|c|c|c|c|c|c|c|c|c|}
\hline \multirow[b]{2}{*}{ Variable } & \multicolumn{2}{|c|}{ Baseline } & \multicolumn{3}{|c|}{$15 \mathrm{~d}$ after intervention } & \multicolumn{3}{|c|}{12 months after intervention } \\
\hline & Mean & SD & Mean & SD & $P$ & Mean & SD & $P$ \\
\hline \multicolumn{9}{|c|}{ Energy intake (kJ/d) } \\
\hline IG & $8503 \cdot 3$ & $1419 \cdot 3$ & $7702 \cdot 4$ & $1393 \cdot 4$ & $<0.001$ & $8112 \cdot 4$ & $1412 \cdot 4$ & 0.048 \\
\hline CG & $8583 \cdot 7$ & $1522 \cdot 4$ & $8702 \cdot 8$ & $1545 \cdot 3$ & 0.632 & $8757 \cdot 9$ & $1608 \cdot 3$ & 0.485 \\
\hline \multicolumn{9}{|c|}{ Total fat intake (\% of energy intake) } \\
\hline IG & $35 \cdot 4$ & $4 \cdot 7$ & $30 \cdot 4$ & $4 \cdot 2$ & $<0.001$ & $31 \cdot 3$ & $4 \cdot 4$ & $<0.001$ \\
\hline CG & $36 \cdot 2$ & $5 \cdot 2$ & $36 \cdot 3$ & $4 \cdot 4$ & 0.889 & $36 \cdot 9$ & $4 \cdot 8$ & 0.343 \\
\hline \multicolumn{9}{|c|}{ Saturated fat intake (\% of energy intake) } \\
\hline IG & $12 \cdot 4$ & $2 \cdot 0$ & $8 \cdot 2$ & $1 \cdot 7$ & $<0.001$ & $10 \cdot 3$ & $1 \cdot 9$ & $<0.001$ \\
\hline $\mathrm{CG}$ & $12 \cdot 8$ & $2 \cdot 3$ & $12 \cdot 4$ & $2 \cdot 4$ & $0 \cdot 267$ & $13 \cdot 4$ & $2 \cdot 8$ & 0.095 \\
\hline \multicolumn{9}{|c|}{ Polyunsaturated fat intake (\% of energy intake) } \\
\hline IG & $6 \cdot 2$ & $1 \cdot 4$ & $6 \cdot 7$ & 1.5 & 0.071 & $6 \cdot 3$ & 1.9 & $0 \cdot 134$ \\
\hline CG & $6 \cdot \overline{3}$ & $1 \cdot 7$ & $6 \cdot 8$ & $1 \cdot 8$ & $0 \cdot 193$ & $6 \cdot 9$ & $2 \cdot 2$ & 0.256 \\
\hline \multicolumn{9}{|c|}{ Monounsaturated fat intake ( $\%$ of energy intake) } \\
\hline IG & $17 \cdot 3$ & 1.9 & $16 \cdot 5$ & $2 \cdot 1$ & 0.056 & $16 \cdot 9$ & 2.5 & $0 \cdot 195$ \\
\hline CG & $17 \cdot 6$ & $1 \cdot 7$ & $17 \cdot 8$ & $1 \cdot 9$ & 0.443 & $18 \cdot 7$ & $2 \cdot 6$ & 0.002 \\
\hline \multicolumn{9}{|c|}{ Protein intake (\% of energy intake) } \\
\hline IG & $15 \cdot 3$ & $1 \cdot 4$ & $18 \cdot 3$ & $1 \cdot 4$ & $<0.001$ & $16 \cdot 7$ & $1 \cdot 8$ & $<0.001$ \\
\hline CG & $14 \cdot 9$ & $1 \cdot 8$ & $15 \cdot 1$ & $1 \cdot 6$ & 0.392 & $15 \cdot 4$ & $1 \cdot 7$ & 0.093 \\
\hline \multicolumn{9}{|c|}{ Carbohydrate intake (\% of energy intake) } \\
\hline IG & $49 \cdot 7$ & $6 \cdot 2$ & $50 \cdot 8$ & $7 \cdot 2$ & 0.343 & $51 \cdot 3$ & $6 \cdot 7$ & 0.078 \\
\hline $\mathrm{CG}$ & $48 \cdot 4$ & $6 \cdot 8$ & $49 \cdot 5$ & $6 \cdot 3$ & 0.231 & $48 \cdot 3$ & $6 \cdot 3$ & 0.944 \\
\hline
\end{tabular}

Table 3 Consumption frequencies of various food categories for the intervention group (IG) and control group (CG) at baseline (September 2007) and re-examination $15 \mathrm{~d}$ (February 2008) and 1 year (February 2009) after the intervention: VYRONAS study

\begin{tabular}{|c|c|c|c|c|c|c|c|c|}
\hline \multirow[b]{2}{*}{ Food category } & \multicolumn{2}{|c|}{ Baseline } & \multicolumn{3}{|c|}{$15 \mathrm{~d}$ after intervention } & \multicolumn{3}{|c|}{12 months after intervention } \\
\hline & Mean & SD & Mean & SD & $P$ & Mean & SD & $P$ \\
\hline \multicolumn{9}{|c|}{ Red meat (meals/week) } \\
\hline IG & $3 \cdot 1$ & $2 \cdot 5$ & $2 \cdot 4$ & $2 \cdot 1$ & 0.028 & $2 \cdot 3$ & $2 \cdot 1$ & 0.021 \\
\hline CG & $3 \cdot 2$ & $2 \cdot 6$ & $2 \cdot 8$ & $1 \cdot 7$ & 0.298 & $2 \cdot 8$ & $1 \cdot 7$ & 0.204 \\
\hline \multicolumn{9}{|c|}{ Poultry (meals/week) } \\
\hline$I G$ & $1 \cdot 6$ & $1 \cdot 8$ & $2 \cdot 1$ & $1 \cdot 7$ & 0.041 & $2 \cdot 3$ & $1 \cdot 8$ & 0.034 \\
\hline CG & 1.5 & $1 \cdot 6$ & $1 \cdot 3$ & $1 \cdot 3$ & 0.363 & $1 \cdot 7$ & 1.5 & 0.393 \\
\hline \multicolumn{9}{|c|}{ Fish (meals/week) } \\
\hline IG & $1 \cdot 3$ & $1 \cdot 1$ & $1 \cdot 2$ & $1 \cdot 1$ & 0.139 & $1 \cdot 2$ & $1 \cdot 3$ & 0.589 \\
\hline CG & 1.5 & $1 \cdot 7$ & $1 \cdot 0$ & 1.5 & $0 \cdot 174$ & $1 \cdot \overline{6}$ & 1.9 & 0.735 \\
\hline \multicolumn{9}{|c|}{ Non-home-made meals (meals/week) } \\
\hline IG & $1 \cdot 2$ & 0.6 & $1 \cdot 1$ & 0.7 & $0 \cdot 259$ & $1 \cdot 0$ & 0.6 & 0.018 \\
\hline $\mathrm{CG}$ & $1 \cdot 3$ & 0.7 & $1 \cdot 2$ & 0.8 & 0.389 & $1 \cdot 4$ & 0.9 & 0.402 \\
\hline \multicolumn{9}{|c|}{ Ready-to-eat breakfast cereals (meals/week) } \\
\hline IG & 0.5 & 0.5 & 0.7 & 0.5 & 0.005 & $0 \cdot 8$ & 0.6 & 0.001 \\
\hline CG & 0.5 & 0.6 & 0.4 & 0.6 & $0 \cdot 218$ & $0 \cdot 7$ & 0.7 & 0.059 \\
\hline \multicolumn{9}{|c|}{ Vegetables (portions/week; $\sim 1 / 2-1$ cup) } \\
\hline IG & $2 \cdot 1$ & $3 \cdot 1$ & 1.9 & $2 \cdot 9$ & 0.149 & $2 \cdot 2$ & $3 \cdot 1$ & 0.413 \\
\hline CG & $2 \cdot 0$ & $3 \cdot 2$ & $1 \cdot 8$ & $2 \cdot 6$ & 0.688 & $2 \cdot 2$ & $2 \cdot 5$ & 0.701 \\
\hline \multicolumn{9}{|c|}{ Fruit (portions/week; $\sim 1 / 2-1$ cup) } \\
\hline IG & $4 \cdot 7$ & 3.5 & $5 \cdot 9$ & $4 \cdot 3$ & 0.036 & $5 \cdot 8$ & $4 \cdot 1$ & 0.048 \\
\hline CG & $4 \cdot 8$ & $3 \cdot 7$ & $5 \cdot 1$ & 3.8 & 0.832 & $4 \cdot 9$ & $3 \cdot 8$ & 0.919 \\
\hline
\end{tabular}

(compared with baseline) was found in the IG. Students of the same group also reported lower total and saturated fat and higher protein daily intake than at the beginning of the study. Except for a significant increase in daily monounsaturated fat intake, no other significant difference in energy intake or all other nutrient components was found in the CG.

The students who underwent the intervention reported that they consumed poultry, ready-to-eat breakfast cereals and fruits more frequently on a weekly basis than they did at baseline. In addition, there was a significant reduction of the weekly frequency of red meat and nonhome-made meals consumption in the same group. No significant difference was found in the frequency of the consumption of any food category in the CG.

Mean BMI decreased significantly (adjusting for age and gender) 12 months after the intervention compared with baseline values in the IG $(23 \cdot 3$ (SD 2.8) $v .24 \cdot 0$ (SD $\left.3 \cdot 1) \mathrm{kg} / \mathrm{m}^{2}, P<0 \cdot 001\right)$, but was not altered in the CG (24.8 (sD 3.8) v. $24 \cdot 3(\mathrm{sD} 3 \cdot 3) \mathrm{kg} / \mathrm{m}^{2}, P=0 \cdot 355$; Fig. 2). 


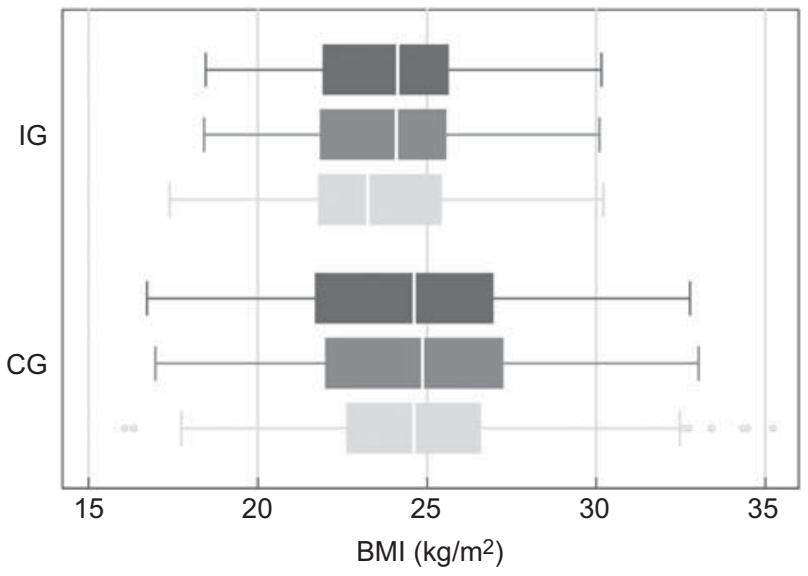

Fig. 2 Box-and-whisker plot of BMI in the intervention group (IG) and the control group (CG) at baseline ( $\square$ ), 15d ( $\square$ ) and 12 months $(\square)$ after the intervention

\section{Discussion}

The present paper describes both the short-term (15-d) and long-term (12-month) effects of a nutrition-behavioural intervention programme for healthy nutrition during adolescence. The findings of the study on students' dietary pattern and BMI continued, to an extent, 12 months after the cessation of the educational programme. The children who underwent the intervention reduced their BMI (long-term effect), reduced their energy, total and saturated fat intakes, while they reported increased protein intake (short- and long-term effects). In addition, the programme was effective in increasing poultry, readyto-eat breakfast cereals and vegetable consumption and decreasing the consumption of red meat and non-homemade meals, both $15 \mathrm{~d}$ (except for the non-home-made meals) and 12 months after the intervention. On the contrary, the children who did not belong to the IG did not change their dietary pattern, while their BMI remained constant. Considering that BMI increases naturally as a child grows up ${ }^{(19)}$, the reduction of BMI that was reported in our study could be an encouraging finding. The results of the study are in line with the results of other health and nutritional education studies ${ }^{(16,33)}$.

The increased consumption of poultry for the IG subjects may explain the increase in the daily proportion of protein intake, since a decrease in red meat intake was reported and no increase in other foods with high protein content was reported in the same group. The increase in protein intake for the IG was not followed by a similar trend in the mean energy intake, which decreased significantly. The decline in mean energy intake for the IG participants seems to be mainly attributed to the decrease in energy derived from total fat, primarily due to the restricted consumption of butter, margarine (not described) and non-home-made meals, rich in saturated fat (snacks, takeaway food, desserts) ${ }^{(34)}$. This hypothesis is further supported by the fact that the consumption of olive oil was not reduced during the study. The aforementioned finding may also explain the fact that the observed proportions of monounsaturated fat intake remained rather constant in both study groups, since olive oil constitutes a large proportion of fat intake in Mediterranean populations and is rich in monounsaturated fat ${ }^{(35)}$. Fruit consumption (including both juice and fruits) rather than vegetable consumption increased significantly over the two phases of the study. This finding is in line with those of other school-based intervention programmes ${ }^{(36)}$ and may be attributed to both children's preference for fruits instead of vegetables $^{(37)}$ and the generally high fruit availability in Greece in all seasons. Another favourable finding for the IG was the increased frequency of ready-to-eat breakfast cereals after the intervention, a result that remained significant until the end of the study. Breakfast cereal consumption has been associated with lower BMI levels and a lower likelihood of overweight/obesity in a sample of Greek adolescents ${ }^{(20)}$ and may also partially explain the significant BMI decrease that was observed in our IG. Fish consumption remained stable in the IG, a rather disappointing finding, considering the nutritional value of this food ${ }^{(38)}$.

The rather positive findings of the study in terms of the effects of the intervention programme on students' health knowledge and dietary attitude improvement may be attributed to both the school-based education curricu$\operatorname{lum}^{(17,25)}$ and the parental involvement to the intervention $^{(25)}$. The teacher-oriented seminars were designed to provide standardized preparatory and teaching materials in order to minimize any bias introduced by potential variability in teachers' delivery ${ }^{(39)}$. The constant supervision of the intervention procedure by family doctors and health visitors assured the compliance with the programme in terms of achieving every session's goals, hours taught, teachers' cooperation and the materials utilized. It should be noticed that teachers' attitude to the project was enthusiastic, they viewed it as a challenge and according to the majority of them 'it was something creative, beyond the usual educational curriculum'. The importance of teachers' input into the programme was clearly explained in the teachers' instruction manual and could be an additional motive for them.

Parental involvement was, similarly to other schoolbased education programmes ${ }^{(40,41)}$, a crucial integral design feature of the study. In addition to the worksheets that the children completed at home with parental collaboration and the material handed to parents, seminars for parents were conducted. The fact that the anthropometric and behavioural findings pertinent to the children were handed to the parents and further discussed during the aforementioned seminars, may have contributed to the high parental participation $(81 \cdot 4 \%)$ at those meetings. Taking into consideration that school meals are not provided in Greek schools, the role of parents in the diet of 
their offspring is rather important and may explain the positive findings of the IG.

The findings of the study should be evaluated considering the high prevalence rates of overweight/obesity among adolescents in Greece as already observed in this urban population ${ }^{(19)}$, where the prevalence rates were found to exceed $18 \%$ for boys and $13 \%$ for girls of similar age. The already described high overweight/obesity rates among Greek adolescents ${ }^{(4)}$ justify the role of such intervention programmes and may partially explain the significant decrease of BMI values in the intervention group, since the current situation leaves room for improvement ${ }^{(42)}$.

Behavioural change is an objective that is both hard to achieve and very satisfying when it is observed ${ }^{(43)}$. The finding that the changes in both children's nutrient intake and type of foods consumed are higher than those described in other studies categorized under the term 'general nutrition education programmes, ${ }^{(44)}$ may be attributed to the design of the aforementioned programmes, since they were totally based on a cognitive approach, rather on the social learning theory used in our study and elsewhere ${ }^{(25)}$.

One strength of the present study was the inclusion of a control group, which was important to draw safe conclusions. An additional strength was the relatively high participation rate in both study groups, even 12 months after the intervention. The implementation of the intervention by the school staff itself as a design feature of the study was another advantage.

The study had some limitations: the small sample size, the short duration of follow-up, incomplete blinding of participants and use of a self-administered questionnaire. Because of to the nature of the intervention (school-based) complete blinding was impossible to achieve. Over- or under-reporting of foods or food groups consumed by the adolescents may bias the reported results due to the nature of data collection (observational study, the participants had to remember what they ate and drank during the last week). In addition, the Vyronas area may represent Greek urban areas, but cannot represent the entire country.

Considering that adolescent obesity persists into adulthood, with all of the associated psychosocial and medical complications ${ }^{(5-7)}$, intervention measures towards healthier dietary habits should be initiated at that stage. Small-scale school-based intervention programmes that do not require significant resources and could be implemented by the school staff in collaboration with family doctors and health visitors could help improve eating behaviour and reduce BMI. It would be interesting if this study could be used a model for future larger-scale interventional attempts.

\section{Acknowledgements}

Sources of funding: The raw material for health promotion activities covering the thematic areas of 'Nutrition-dietary habits' and 'Physical activity and health' was funded by the Ministry of Education and the National Foundation for the Youth. Conflict of interest: None declared. Authors' contributions: C.M. had primary responsibility for conception, participant screening, data interpretation and writing the manuscript. A.M., T.M.-S. and Y.T. supervised the design and execution of the study, made the preliminary data analysis and contributed to the writing of the manuscript. Y.M. was responsible for protocol development, framework and outcome assessment and contributed to the writing of the manuscript. A.N. was responsible for outcome assessment and contributed to the writing of the manuscript. A.A. was responsible for the statistical analysis and contributed to the writing of the manuscript. Acknowledgements: The authors would like to thank all students, parents and teachers of the high schools of Vyronas who participated in this study and the health visitors and doctors who supervised the whole procedure and performed the data collection.

\section{References}

1. Lobstein T \& Jackson-Leach R (2007) Child overweight and obesity in the USA: prevalence rates according to IOTF definitions. Int J Pediatr Obes 2, 62-64.

2. Martin JJ, Hernandez LS, Gonzalez MG, Mendez CP, Rey Galan C \& Guerrero SM (2008) Trends in childhood and adolescent obesity prevalence in Oviedo (Asturias, Spain) 1992-2006. Acta Paediatr 97, 955-958.

3. Juliusson PB, Roelants M, Eide GE, Hauspie R, Waaler PE \& Bjerknes R (2007) Overweight and obesity in Norwegian children: secular trends in weight-for-height and skinfolds. Acta Paediatr 96, 1333-1337.

4. Lobstein T \& Frelut ML (2003) Prevalence of overweight among children in Europe. Obes Rev 4, 195-200.

5. Bibbins-Domingo K, Coxson P, Pletcher MJ, Lightwood J \& Goldman L (2007) Adolescent overweight and future adult coronary heart disease. $N$ Engl J Med 357, 2371-2379.

6. Li S, Chen W, Srinivasan SR \& Berenson GS (2004) Childhood blood pressure as a predictor of arterial stiffness in young adults: the Bogalusa Heart Study. Hypertension 43, 541-546.

7. Raitakari OT, Juonala M, Kahonen M et al. (2003) Cardiovascular risk factors in childhood and carotid artery intima-media thickness in adulthood: the Cardiovascular Risk in Young Finns Study. JAMA 290, 2277-2283.

8. Thomas C, Hypponen E \& Power C (2008) Obesity and type 2 diabetes risk in midadult life: the role of childhood adversity. Pediatrics 121, e1240-e1249.

9. Kafatos A \& Mamalakis G (1993) Changing patterns of fat intake in Crete. Eur J Clin Nutr 47, Suppl. 1, S21-S24.

10. Voukiklaris GE, Kafatos A \& Dontas AS (1996) Changing prevalence of coronary heart disease risk factors and cardiovascular diseases in men of a rural area of Crete from 1960 to 1991. Angiology 47, 43-49.

11. Kaur H, Hyder ML \& Poston WS (2003) Childhood overweight: an expanding problem. Treat Endocrinol 2, $375-388$.

12. Micic D (2001) Obesity in children and adolescents - a new epidemic? Consequences in adult life. J Pediatr Endocrinol Metab 14, Suppl. 5, 1345-1352.

13. Law M (2000) Dietary fat and adult diseases and the implications for childhood nutrition: an epidemiologic approach. Am J Clin Nutr 72, 5 Suppl., 1291S-1296S.

14. Pitsavos C, Panagiotakos DB, Chrysohoou C, Skoumas J, Papaioannou I, Stefanadis C \& Toutouzas PK (2002) The 
effect of Mediterranean diet on the risk of the development of acute coronary syndromes in hypercholesterolemic people: a case-control study (CARDIO2000). Coron Artery Dis 13, 295-300.

15. Ask AS, Hernes S, Aarek I, Johannessen G \& Haugen M (2006) Changes in dietary pattern in 15 year old adolescents following a 4 month dietary intervention with school breakfast - a pilot study. Nutr J 5, 33 .

16. Harrell TK, Davy BM, Stewart JL \& King DS (2005) Effectiveness of a school-based intervention to increase health knowledge of cardiovascular disease risk factors among rural Mississippi middle school children. South Med $J$ 98, 1173-1180.

17. Manios Y \& Kafatos A (2006) Health and nutrition education in primary schools in Crete: 10 years follow-up of serum lipids, physical activity and macronutrient intake. Br J Nutr 95, 568-575.

18. Giannakopoulos G, Panagiotakos D, Mihas C \& Tountas Y (2009) Adolescent smoking and health-related behaviours: interrelations in a Greek school-based sample. Child Care Health Dev 35, 164-170.

19. Kosti RI, Panagiotakos DB, Mihas CC, Alevizos A, Zampelas A, Mariolis A \& Tountas Y (2007) Dietary habits, physical activity and prevalence of overweight/obesity among adolescents in Greece: the Vyronas study. Med Sci Monit 13, CR437-CR444.

20. Kosti RI, Panagiotakos DB, Zampelas A, Mihas C, Alevizos A, Leonard C, Tountas Y \& Mariolis A (2008) The association between consumption of breakfast cereals and BMI in schoolchildren aged 12-17 years: the VYRONAS study. Public Health Nutr 11, 1015-1021.

21. Kourlaba G, Panagiotakos DB, Mihas K, Alevizos A, Marayiannis K, Mariolis A \& Tountas Y (2009) Dietary patterns in relation to socio-economic and lifestyle characteristics among Greek adolescents: a multivariate analysis. Public Health Nutr 12, 1366-1372.

22. Mihas C, Mariolis A, Manios Y, Naska A, Panagiotakos D, Arapaki A, Alevizos A, Mariolis-Sapsakos T \& Tountas Y (2009) Overweight/obesity and factors associated with body mass index during adolescence: the VYRONAS study. Acta Paediatr 98, 495-500.

23. National Statistical Service of Greece (2007) Statistical Data. http://www.statistics.gr/StatMenu_eng.asp (accessed March 2009).

24. Nemet D, Barkan S, Epstein Y, Friedland O, Kowen G \& Eliakim A (2005) Short- and long-term beneficial effects of a combined dietary-behavioural-physical activity intervention for the treatment of childhood obesity. Pediatrics 115, e443-e449.

25. Walter HJ \& Wynder EL (1989) The development, implementation, evaluation, and future directions of a chronic disease prevention program for children: the 'Know Your Body' studies. Prev Med 18, 59-71.

26. Manios Y \& Kafatos A (1999) Health and nutrition education in elementary schools: changes in health knowledge, nutrient intakes and physical activity over a six year period. Public Health Nutr 2, 445-448.

27. Bandura A (2001) Social cognitive theory: an agentic perspective. Annu Rev Psychol 52, 1-26.

28. Perry CL, Baranowski T \& Parcel G (1990) How individuals, environments and health behaviour interact: social learning theory. In Health Behavior and Health Education: Theory, Research and Practice, pp. 161-184 [K Glanz, FM Lewis and BK Rimer, editors]. San Francisco, CA: Jossey-Bass.
29. Perry CL, Luepker RV, Murray DM, Kurth C, Mullis R, Crockett S \& Jacobs DR Jr (1988) Parent involvement with children's health promotion: the Minnesota Home Team. Am J Public Health 78, 1156-1160.

30. Cole TJ, Bellizzi MC, Flegal KM \& Dietz WH (2000) Establishing a standard definition for child overweight and obesity worldwide: international survey. BMJ 320, $1240-1243$.

31. US Department of Agriculture (2008) USDA National Nutrient Database for Standard Reference, Release 21. http://www.ars.usda.gov/ba/bhnrc/ndl (accessed March 2009).

32. Preventive Medicine and Nutrition Clinic of the University of Crete (2001) Nutrient tables of Greek foods (in Greek). http://nutrition.med.uoc.gr/GreekTables/Main/main.htm (accessed March 2009).

33. Harrell JS, McMurray RG, Gansky SA, Bangdiwala SI \& Bradley CB (1999) A public health vs a risk-based intervention to improve cardiovascular health in elementary school children: the Cardiovascular Health in Children Study. Am J Public Health 89, 1529-1535.

34. O'Donnell SI, Hoerr SL, Mendoza JA \& Tsuei Goh E (2008) Nutrient quality of fast food kids meals. Am J Clin Nutr $\mathbf{8 8}$, $1388-1395$.

35. Ferro-Luzzi A, James WP \& Kafatos A (2002) The high-fat Greek diet: a recipe for all? Eur J Clin Nutr 56, 796-809.

36. Angelopoulos PD, Milionis HJ, Grammatikaki E, Moschonis G \& Manios Y (2009) Changes in BMI and blood pressure after a school based intervention: The CHILDREN study. Eur J Public Health 19, 319-325.

37. Baxter SD \& Thompson WO (2002) Fourth-grade children's consumption of fruit and vegetable items available as part of school lunches is closely related to preferences. $J$ Nutr Educ Behav 34, 166-171.

38. Aberg MA, Aberg N, Brisman J, Sundberg R, Winkvist A \& Toren K (2009) Fish intake of Swedish male adolescents is a predictor of cognitive performance. Acta Paediatr $\mathbf{9 8 ,}$ $555-560$

39. Bush PJ, Zuckerman AE, Theiss PK, Taggart VS, Horowitz C, Sheridan MJ \& Walter HJ (1989) Cardiovascular risk factor prevention in black schoolchildren: two-year results of the 'Know Your Body' program. Am J Epidemiol 129, 466-482.

40. Manios Y, Moschandreas J, Hatzis C \& Kafatos A (1999) Evaluation of a health and nutrition education program in primary school children of Crete over a three-year period. Prev Med 28, 149-159.

41. Luepker RV, Perry CL, McKinlay SM et al. (1996) Outcomes of a field trial to improve children's dietary patterns and physical activity. The Child and Adolescent Trial for Cardiovascular Health. CATCH collaborative group. JAMA 275, 768-776.

42. Kafatos A, Manios Y \& Moschandreas J (2005) Health and nutrition education in primary schools of Crete: follow-up changes in body mass index and overweight status. Eur J Clin Nutr 59, 1090-1092.

43. Higginbotham J (1992) Necessities for evaluating behavior change in health promotion/disease prevention programs: knowledge, skill, and attitude. Fam Community Health 15, $41-56$.

44. Graves K, Shannon B, Sims L \& Johnson S (1982) Nutrition knowledge and attitudes of elementary school students after receiving nutrition education. J Am Diet Assoc 81, 422-427. 